\title{
Malignant epithelial tumours associated with autoimmune sialadenitis
}

\author{
PD JAMES, IO ELLIS \\ From the Department of Histopathology, University Hospital, Nottingham
}

SUMMARY Malignant epithelial tumours associated with autoimmune sialadenitis are rare in white races but occur more often in those of Eskimo or oriental descent. Ultrastructurally these tumours are squamous in origin, and they may arise from the epithelial component of autoimmune sialadenitis. The two cases reported are the first described in natives of this country, and in one, a case of parotid tumour, autoimmune sialadenitis preceded the development of undifferentiated carcinoma by 12 years; the other, a submandibular lesion, indicates some diagnostic difficulties that were found. This condition deserves wider recognition, as adequate primary treatment may result in long term survival.

In 1952 Godwin" introduced the term "benign lymphoepithelial lesion" to describe a lymphoid infiltrate of salivary tissue associated with glandular atrophy and proliferation of salivary duct elements to form islands of epithelial cells. This process is now accepted as an autoimmune disease ${ }^{2}$ and there is an increased incidence in the subsequent development both of carcinomas and malignant lymphomas. ${ }^{3}$ Malignant epithelial tumours associated with autoimmune sialadenitis are less common than malignant lymphomas and show geographic and ethnic predispositions. Over 50 cases have been reported, most having occurred in Eskimos, with additional reports from Japan and China.

We report two cases of malignant epithelial tumours associated with autoimmune sialadenitis, which we believe to be the first described in Britain. In one case a salivary lesion diagnosed as autoimmune sialadenitis had been removed from the parotid 12 years before the subsequent development of an undifferentiated carcinoma. The second case pinpoints some of the diagnostic difficulties, and, we believe, reflects a lack of awareness and possible underdiagnosis of this condition.

\section{Case reports}

CASE 1

A 60 year old man of Scottish descent presented with a five month history of a rapidly growing lump in the

Accepted for publication 16 January 1986 right parotid region with more recent pain in the ear. He had no other complaints and examination showed a right parotid swelling. A superficial parotidectomy was performed, and the surgical specimen received showed a well circumscribed yellow tumour $3.5 \mathrm{~cm}$ in diameter with surrounding salivary tissue and adjacent enlarged lymph nodes. He was alive and well two years postoperatively.

Twelve years previously he had complained of swelling in the right parotid region, and at operation a soft mass $2.0 \mathrm{~cm}$ in diameter was removed from within the lower pole of the parotid gland. He had no other symptoms at that time. Histology showed a small amount of atrophic salivary gland at the periphery, but the major part consisted of lymphoid tissue with islands of epithelial cells diagnosed as autoimmune sialadenitis.

The more recent lesion showed residual atrophic salivary gland and foci of lymphoid tissue with epithelial elements typical of autoimmune sialadenitis at the periphery (Fig. 1). In addition, hyperplastic and variably atypical epithelial elements that were producing multilayered duct like structures containing desquamated cellular debris were seen (Fig. 2). These merged into islands of solid undifferentiated carcinoma separated by fibrous trabeculae containing a lymphocytic and plasma cell infiltrate (Fig. 3). The tumour cells were round, oval, and spindle shaped with large pleomorphic nuclei and numerous mitoses (Fig. 4). In places tumour cells had a clear vacuolated cytoplasm and showed foci of keratinisation (Fig. 5). Metastatic tumour was present in adjacent lymph nodes attached to the main specimen. 


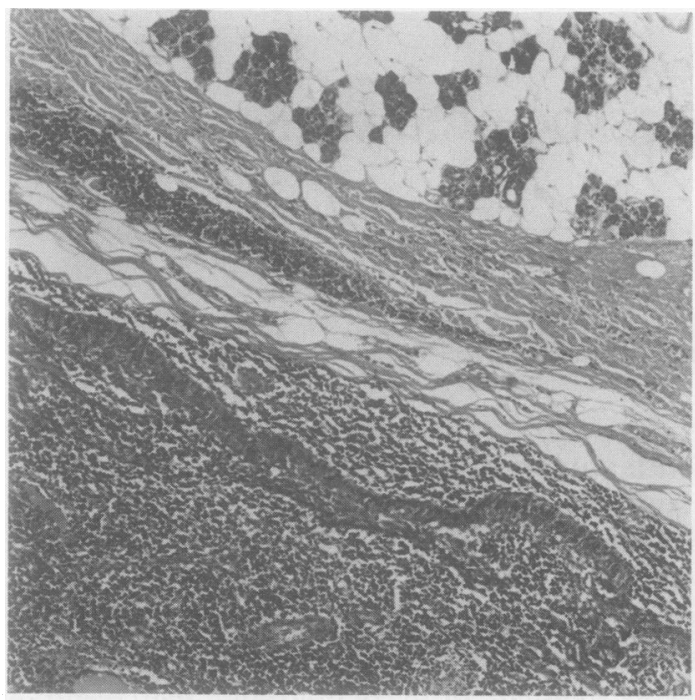

Fig. 1 Case 1. Atrophic salivary tissue with epithelial islands within lymphoid stroma at periphery of surgical specimen. (Haematoxylin and eosin.) $\times 50$.

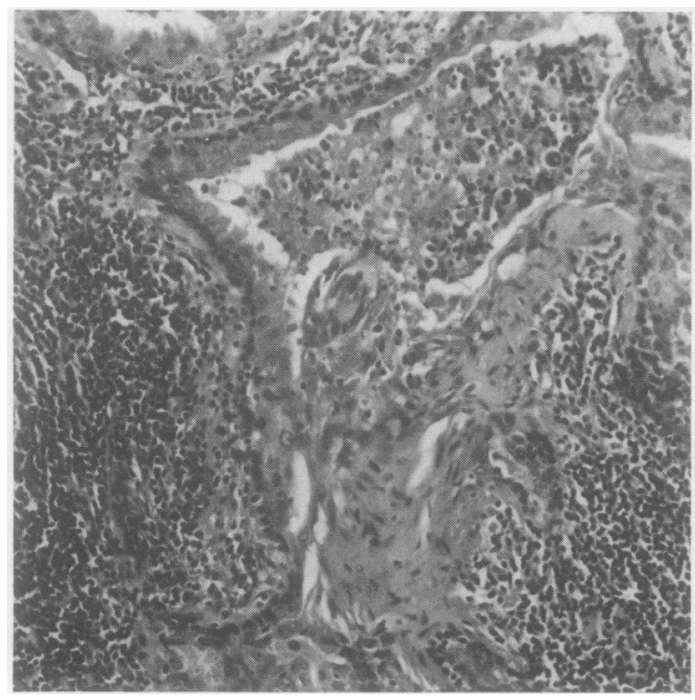

Fig. 2 Multilayered duct like structure containing desquamated cellular debris. (Haematoxylin and eosin.) $\times 126$.

CASE 2

A 69 year old English woman presented with a left sided swelling below the angle of the jaw that had gradually enlarged over the previous six months. A small persistent ulcer on the frenulum of the tongue related to her dentures was found, but this resolved with conservative treatment. She had a history of

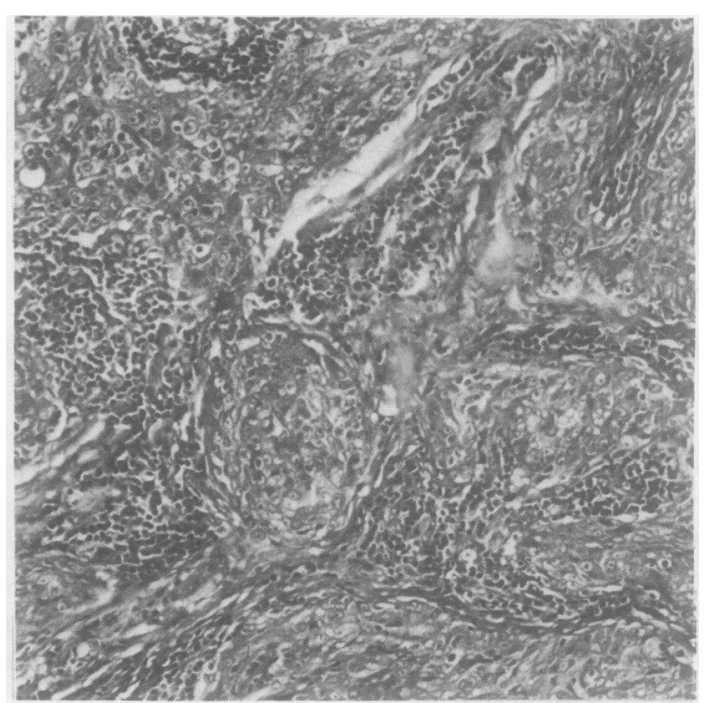

Fig. 3 Undifferentiated carcinoma separated by fibrous trabeculae containing lymphocytic infiltrate. (Haematoxylin and eosin.) $\times 126$.

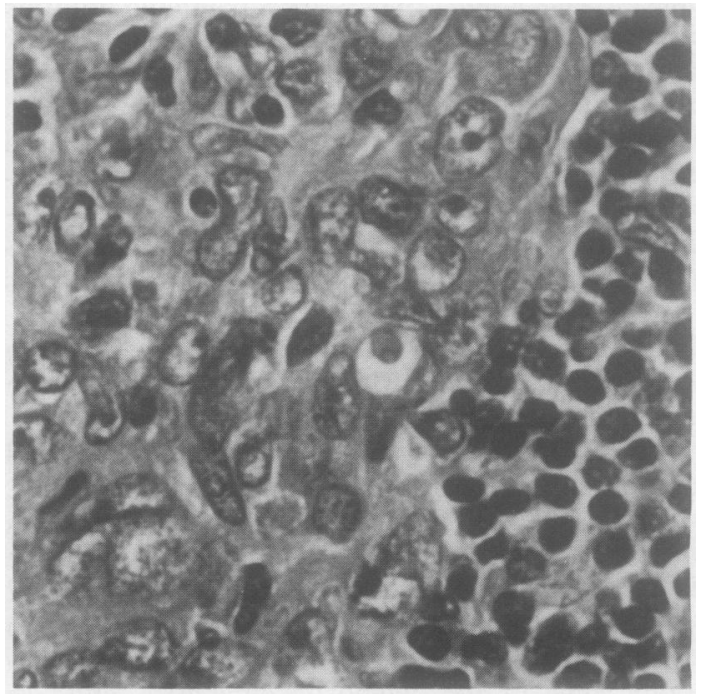

Fig. 4 Pleomorphic malignant cells with adjacent

lymphocytic infiltrate. (Haematoxylin and eosin.) $\times 720$.

arthritis requiring non-steroidal anti-inflammatory drugs.

A submandibular mass was excised and subsequent $T$ investigations including endoscopy of the nasopharynx, trachea, oesophagus, and stomach showed no other abnormality. The neck was reexplored one month later because of persistent swell- 


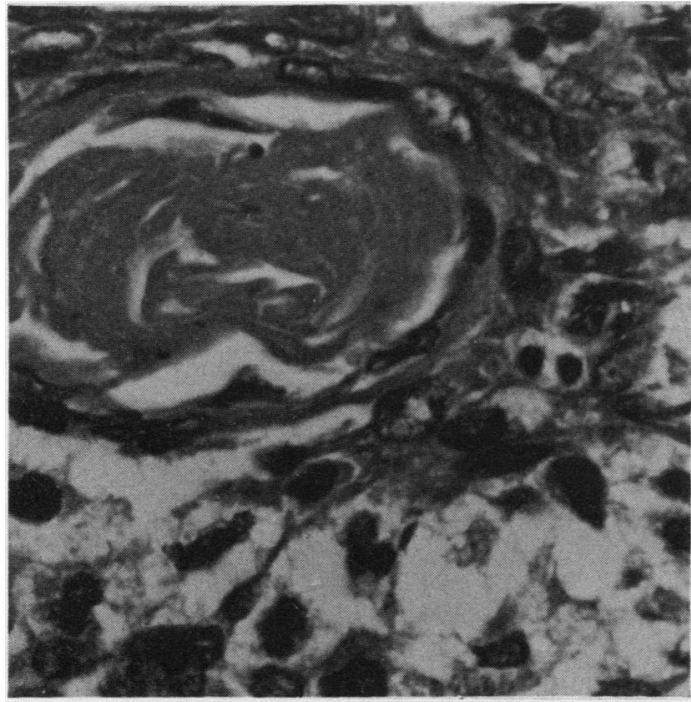

Fig. 5 Focal keratinisation; adjacent tumour cells have clear, vacuolated cytoplasm. (Haematoxylin and eosin.) $\times 720$.

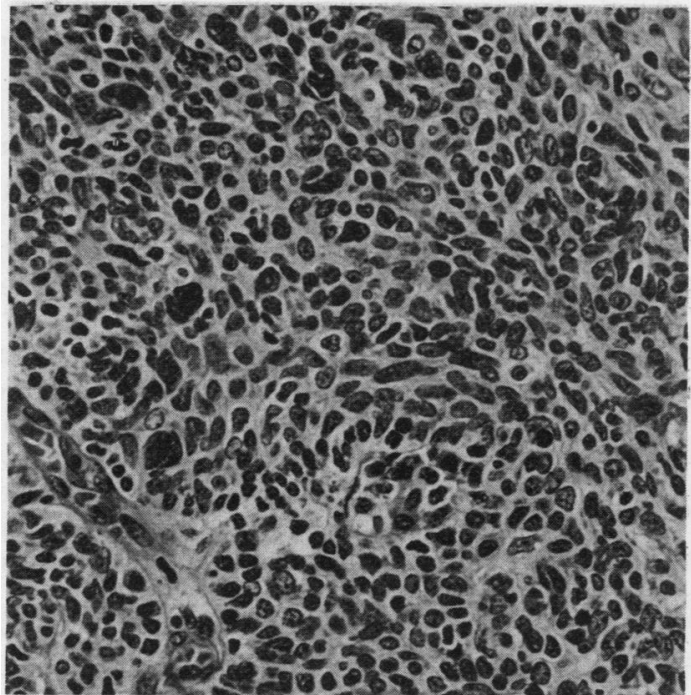

Fig. 6 Case 2. Pleomorphic undifferentiated tumour with conspicuous mitoses. (Haematoxylin and eosin.) $\times 290$.

ing, but biopsy showed no evidence of residual disease. She was alive and well with no recurrence of her disease nine months after the biopsy.

The surgical specimen was an encapsulated mass 3 $\times 2 \times 2 \mathrm{~cm}$ composed of solid sheets and anastomosing cords of cells, with an intervening fibrovascular stroma containing a focal lymphocytic infiltrate. The tumour cells were rounded, oval, or

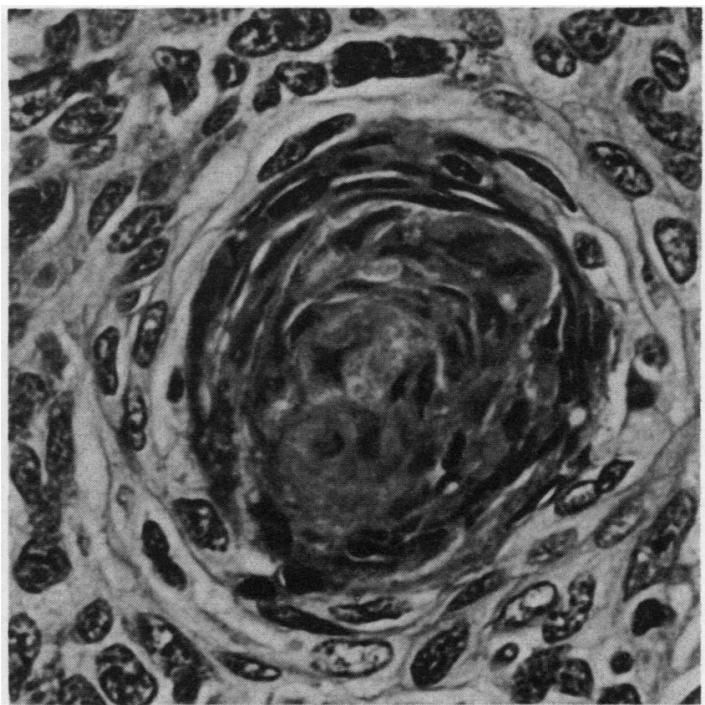

Fig. 7 Focal keratinisation with "pearl" formation.

(Haematoxylin and eosin.) $\times 680$

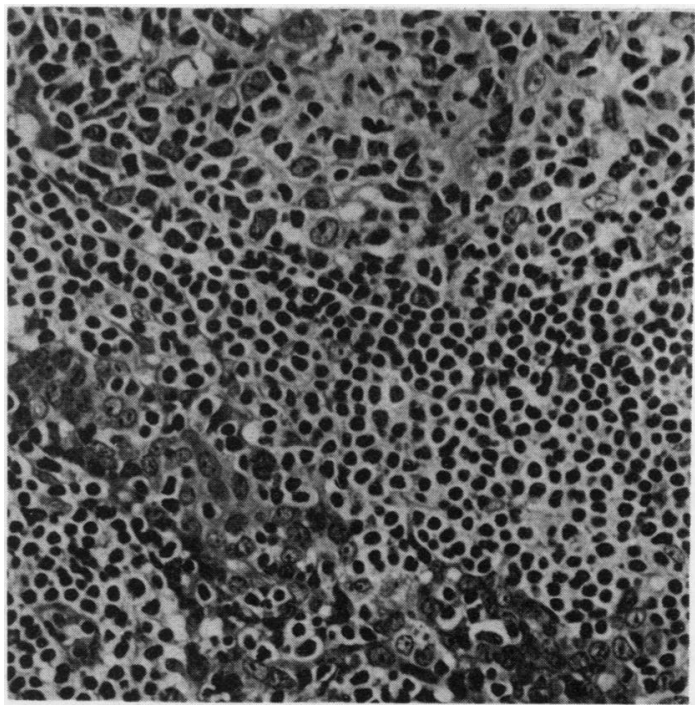

Fig. 8 Periphery of tumour showing island of epithelium surrounded and infiltrated by lymphoid cells, features typical of autoimmune sialadenitis. (Haematoxylin and eosin.) $\times 290$.

spindle shaped with large pleomorphic nuclei and conspicuous mitoses (Fig. 6); focal keratinisation with "pearl" formation was also present (Fig. 7). Cords and islands of less atypical epithelial cells were seen at the periphery, separated and focally infiltrated by lymphocytes (Fig. 8), an appearance that is characteristic of autoimmune sialadenitis. Fresh tissue appropriately fixed and processed was available for 


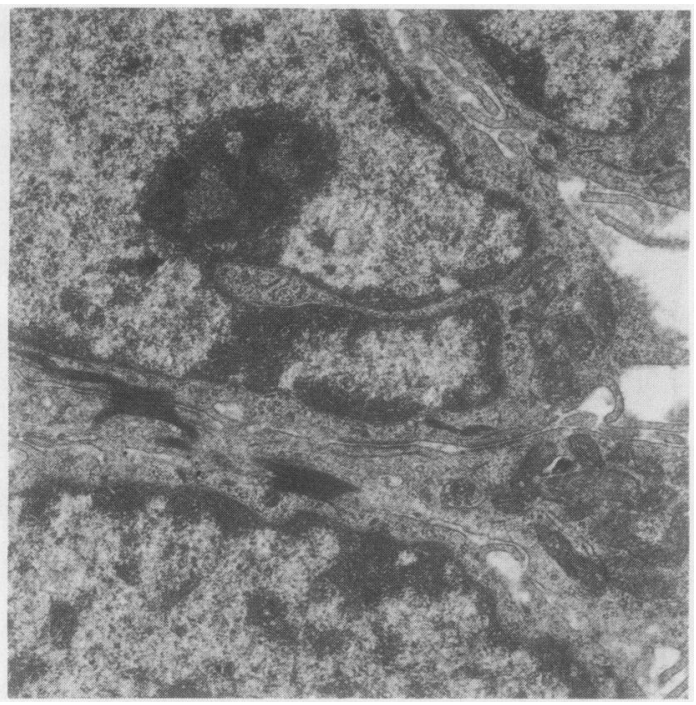

Fig. 9 Squamous differentiation is shown by desmosome formation and presence of prominent tonofilament bundles. Electron micrograph $\times 23500$.

ultrastructural examination, and tumour cells showed squamous differentiation with well formed desmosomes and prominent tonofilament bundles (Fig. 9).

\section{Discussion}

The benign lymphoepithelial lesion described by Godwin $^{1}$ is an autoimmune disease ${ }^{2}$ affecting salivary tissue; and it may occur with or without the clinical picture of Sjogren's syndrome. The term benign is misleading because of the association with malignant lymphoma, and this risk in patients with Sjogren's syndrome is estimated to be $\mathbf{4 3 . 8}$ times greater than that of a comparable normal population. ${ }^{4}$ Various terms have been introduced to describe this condition including immunosialadenitis, ${ }^{2}$ myoepithelial sialadenitis, ${ }^{3}$ and autoimmune sialadenitis. ${ }^{5}$ Recent work has shown that the "myoepithelial" islands contain metaplastic epithelial cells but no demonstrable myoepithelial cells. ${ }^{6}$ We do not propose to review this entity, its terminology, or the incidence of malignant lymphomas but will draw attention to malignant epithelial tumours arising in association with "autoimmune sialadenitis".

Hilderman $e t \mathrm{al}^{7}$ reported an undifferentiated carcinoma of the parotid salivary gland with a lymphoid stroma that resembled the benign lymphoepithelial lesion described by Godwin. ${ }^{1}$ This was considered to be the malignant counterpart of Godwin's benign lesion and was termed malignant lymphoepithelial lesion with carcinomatous component. Over 50 similar cases have now been reported worldwide. ${ }^{8-22}$ 을 Most have occurred in Eskimos and orientals, with the parotid the most common site of origin, although $\frac{0}{9}$ some cases arise in the submandibular gland.

Patients are commonly middle aged, but the range $\frac{}{0}$ varies, with occasional cases occurring in the second $\frac{\bar{\omega}}{\frac{5}{5}}$ decade of life. ${ }^{819}$ The tumours are undifferentiated $\stackrel{\square}{\Omega}$ carcinomas, often with a nodular gross appearance and cells arranged in cords, sheets, or nests separated

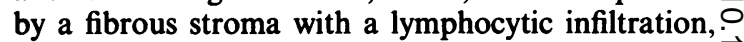
which sometimes spills over into the tumour. The cells $\overrightarrow{\vec{\omega}}$ usually show no differentiating features, but ultrastructural studies indicate that they are of squamous origin. ${ }^{17202223}$ In some cases ${ }^{101119}$ a benign lymphoepithelial lesion had been removed several or years before the subsequent development of the undifferentiated carcinoma while in others $^{13151719-22}$ residual areas of benign lympho-음 epithelial lesion have been described.

On purely morphological grounds there is evidence $\bar{z}$ to indicate that these undifferentiated carcinomas arise within salivary tissue affected by autoimmune $\vec{\theta}$ sialadenitis. It seems that they may arise from the epithelial component of autoimmune sialadenitis by a progression of metaplasia, to dysplasia, to frank invasive malignancy. Severe epithelial dysplasia in parallel with benign ductal elements has been described in association with these tumours, ${ }^{1721}$ and $\stackrel{\circ}{\odot}$ atypia within the epithelial islands was present in our 0 cases. Interestingly, only one of the patients described $\vec{O}$ in the published reports had symptoms of Sjogren's 3 syndrome, and this case is the only adenocarcinoma that has been described. ${ }^{9}$

Our two cases are typical of this condition but illustrate additional points of interest. One case presented with autoimmune sialadenitis, and although this has 3 . been previously reported, ${ }^{1011} 19$ the 12 year intervalio before the development of malignancy is the longest $₹$ latent period described. Even on reviewing the origi-o nal histology there was no way in which the malig-? nant transformation might have been predicted. In $\frac{7}{2}$ both cases areas of residual autoimmune sialadenitis were present at the periphery of the tumour, and in $N$ one case transition of the epithelial elements through N squamous metaplasia and dysplasia could be seen. N The tumours were unusual as both showed kera- $\omega$ tinisation. A malignant epithelial tumour associated with autoimmune sialadenitis was confidently diag- - ? nosed in one patient (case 1), based on the history of autoimmune sialadenitis, the histological features of the presenting tumour, and the presence of residual ${ }_{0}^{0}$ autoimmune sialadenitis with adjacent atrophic sali- $\frac{\vec{\Phi}}{\Phi}$ vary tissue. The diagnosis was more difficult in case $2 \stackrel{\frac{\rho}{\mathrm{D}}}{\mathrm{O}}$ and was made only after wide consultation. No sali- $\varrho$ vary tissue was present in the specimen received,? 
which was interpreted as being a lymph node. It was replaced by sheets and islands of undifferentiated carcinoma, which showed focal squamous differentiation with an intervening fibrovascular stroma containing a lymphocytic infiltrate. At the periphery of the tumour, islands of hyperplastic epithelium with a lymphoid stroma were identified with appearances typical of autoimmune sialadenitis. Ultrastructural studies in case 2 showed desmosomes and tonofilament bundles indicating squamous differentiation, findings in keeping with previously published data. ${ }^{17202223}$

These problems in diagnosis led us to consider that this may be a poorly recognised and underdiagnosed entity. We have identified only eight reported cases in the world that have occurred in caucasians, ${ }^{71013151721}$ and no cases of malignant epithelial tumours associated with autoimmune sialadenitis were reported in a recent review of 2410 salivary gland tumours from Britain. ${ }^{24}$ The absence of salivary tissue and paucity of autoimmune sialadenitis elements may obscure the lesion's true origin and lead to a misdiagnosis - metastatic carcinoma in a lymph node. Metastasic invasions of the parotid gland or parotid associated lymphoid tissue do occur, but submandibular metastases are exceptionally rare. ${ }^{25}$ These tumours bear a striking resemblance to nasopharyngeal carcinomas ${ }^{1620}$ and further clinical investigation may be necessary to exclude the presence of an underlying carcinoma in the upper oral and nasal pharynx. The finding of sheets and islands of undifferentiated carcinoma separated by lymphoid stroma should alert the pathologist to the possibility of a malignant epithelial tumour associated with autoimmune sialadenitis. Subsequent search of tissue sections for residual autoimmune sialadenitis or salivary tissue may be fruitful and help in the diagnosis.

The geographical distribution of this otherwise rare salivary gland tumour is of great interest. Most cases have been reported in north American ${ }^{811} 1422$ and Greenland Eskimos ${ }^{16}$ with case reports from China ${ }^{19}$ and Japan. ${ }^{20}$ There is no satisfactory explanation for the high incidence in Eskimos, although the possibility of vitamin A deficiency has been suggested. ${ }^{16} \mathrm{~A}$ high incidence of nasopharyngeal carcinoma has been described from China ${ }^{19}$ and Greenland ${ }^{16}$ and it is suggested that Epstein-Barr virus infection may be a factor in the development of these salivary neoplasms. ${ }^{1623}$

Most patients have been treated with surgery alone, although a minority have received radiotherapy and also chemotherapy. ${ }^{20}$ Prognosis is difficult to assess with these different regimens from various centres. The outlook for an undifferentiated neoplasm might seem poor, and the natural history is one of local nodal metastases and ultimately widespread meta- static disease. With radical local treatment, however, long term survival is possible. Two thirds of the reported patients were alive from eight months to 10.5 years after initial treatment, only one third dying from metastatic disease. Only one ${ }^{7}$ of the eight caucasian patients described 813151721 died from the disease; survival varied from 20 months to 12 years.

We are grateful to Professor RE Cotton for his comments on the paper. We thank Mr Bill Brackenbury for the photomicrographs and Mrs Margaret E Norris for preparation of the manuscript.

\section{References}

${ }^{1}$ Godwin JT. Benign lymphoepithelial lesion of the parotid gland (adenolymphoma, chronic inflammation, lymphoepithelioma, lymphocytic tumour, Mikulicz disease). Report of eleven cases. Cancer 1952;5:1089-103.

${ }^{2}$ Siefert G, Donath K. Die Morphologie der Speicheldrusenerkrankungen. Arch Otorhinolaryngol 1976;213:111-208.

${ }^{3}$ Schmid U, Helbron D, Lennert $\mathrm{K}$. Development of malignant lymphoma in myoepithelial sialadenitis (Sjogren's syndrome). Virchows Arch (Pathol Anat) 1982;395:11-43.

${ }^{4}$ Kassan SS, Thomas TL, Moutsopoulos HM, et al. Increased risk of lymphoma in sicca syndrome. Ann Intern Med 1978;89:888-92.

${ }^{5}$ Ostberg Y. The clinical picture of benign lympho-epithelial lesion. Clin Otolaryngol 1983;8:381-90.

${ }^{6}$ Kjorell U, Ostberg Y. Distribution of intermediate filaments and actin microfilaments in parotid autoimmune sialadenitis of Sjogren syndrome. Histopathology 1984;8:991-1011.

${ }^{7}$ Hilderman WC, Gordon JS, Large HL, Carroll CF. Malignant lymphoepithelial lesion with carcinomatous component apparently arising in parotid gland. A malignant counterpart of benign lymphoepithelial lesion? Cancer 1962;15:606-10.

${ }^{8}$ Wallace AC, MacDougall JT, Hildes JA, Lederman JM. Salivary gland tumours in Canadian Eskimos. Cancer 1963;16:1338-53.

9 Delaney WE, Balogh K Jr. Carcinoma of the parotid gland associated with benign lymphoepithelial lesion (Mikulicz's disease) in Sjogren's syndrome. Cancer 1966;19:853-60.

10 Gravanis MB, Giansanti JS. Malignant histological counterpart of the benign lymphoepithelial lesion. Cancer 1970;26:1332-42.

11 Arthaud JB. Anaplastic parotid carcinoma ("malignant lymphoepithelial lesion") in seven Alaskan natives. Am J Clin Pathol 1972;57:275-86.

12 Schnitzer B, Weaver DK. In: Batsakis JG, ed. Tumours of the head and neck: clinical and pathological considerations. Baltimore: Williams and Wilkins, 1974:376.

13 Batsakis JG, Bernacki EG, Rice DH, Stebber ME. Malignancy and the benign lymphoepithelial lesion. Laryngoscope 1975;85:389-99.

14 Sinha BK, Buntine DW. Parotid gland tumours. Clinicopathologic study. Am J Surg 1975;129:675-81.

15 Ferlito A, Fiore Donati L. Malignant lymphoepithelial lesions (undifferentiated ductal carcinoma of the parotid gland). Three case reports and review of the literature. J Laryngol Otol 1977;91:869-85.

16 Nielson NH, Mikkelsen F, Hansen JPH. Incidence of salivary gland neoplasms in Greenland with special reference to an anaplastic carcinoma. Acta Pathol Microbiol Scand (A) 1978;86:185-93.

${ }^{17}$ Redondo C, Garcia A, Varquez F. Malignant lymphoepithelial lesion of the parotid gland: poorly differentiated squamous cell carcinoma with lymphoid stroma. Cancer 1981;48:289-92. 
18 Roncevic R, Tatic V. Malignant lymphoepithelial lesion: report of a case. J Oral Surg 1981;39:449-50.

19 Hanji D, Gohao L. Malignant lymphoepithelial lesions of the salivary glands with anaplastic carcinomatous change. Report of nine cases and review of literature. Cancer 1983;52:2245-52.

20 Nagao K, Matsuzaki O, Saiga H, et al. A histopathologic study of benign and malignant lymphoepithelial lesions of the parotid gland. Cancer 1983;52:1044-52.

21 Amaral ALMP, Nascimento AG. Malignant lymphoepithelial lesion of the submandibular gland. Oral Surg 1984;58:184-90.

22 Yazdi HM, Hogg GR. Malignant lymphoepithelial lesion of the submandibular salivary gland. Am J Clin Pathol 1984;82:344-8.

${ }^{23}$ Sehested M, Hainau B, Albeck H, Nielsen NH, Hansen JPH.
Ultrastructural investigation of anaplastic salivary gland carcinomas in Eskimos. Cancer 1985;55:2732-6.

24 Eveson JW, Cawson RA. Salivary gland tumours. A review of 2410 cases with particular reference to histological types, site, age and sex distribution. $J$ Pathol 1985;146:51-8.

${ }^{25}$ Evans RW, Cruickshank AH. Epithelial tumours of the salivary glands. In: Bennington JL, ed. Major problems in pathology. Vol. 1. Philadelphia: WB Saunders 1970.

Requests for reprints to: Dr PD James, Department of Pathology, University Hospital, Queen's Medical Centre, Nottingham NG7 2UH, England. 